\title{
DISTRIBUTIVE JUSTICE AND ALLOCATION BY THE MARKET: ON THE CHARACTERISATION OF A FAIR MARKET ECONOMY
}

\author{
Tapan BISWAS \\ Department of Economics, Queen's University, Kingston, Ontario. $K 7 L$ ivo Canada and \\ Department of Economics, University of Hull, Hull HU6 $7 R X$ U.K. \\ Communicated by D.J. Mayston \\ Received 15 January 1986 \\ Revised 3 November 1986
}

\begin{abstract}
After critically examining different notions of fairness in allocating goods and leisure in an economy with production, the paper considers an alternative approach to distributive justice and discusses the concept of a fair market economy (EAFME).
\end{abstract}

Key words: Distributive justice, market economy, fairness, efficienc!

\section{Introduction}

Achieving social and economic justice for its members is one of the most cherished goals of every civilized society. The concept of justice itself implies the existence of certain values which the society deems as just. In nineteenth century England, the principle of distributive justice was identified with the principle that 'happiness' should be distributed amongst people in such a way that the sum-total of happiness is maximised. This Benthamite principle of 'utilitarianism' was so much deep-rooted in the nineteenth cent ury social philosophy in England that Nietzsche once remarked with sarcasm that 'Man does not want happiness, only an Englishman does!' At the end of the twentieth century, we are aware of several problems with the utilitarian approach. First, there is a problem of measuring utility. Second, even if utility is measurable, there is a problem with interpersonal comparison of utility. Third, in the theory of distributive justice, we are interested not only with the sum total of utility or happiness but also how it is distributed amongst the members of the society. In relatively recent past Foley (1967) came up with a remarkably simple and elegant definition of a 'fair' or 'equitable' allocation. According to Foley, an allocaLion is 'equitable' if it is characterised by the absence of envy among the participating agents. The approach provided us with a criterion of distributive justice which had its root in the utilitarian philosophy but was not plagued with the shortcomings of utilitarianism as mentioned above. It also provided a seemingly acceplable 'utilitarian' theory of distributive justice vis-a-vis the contractual theory of 
justice (see Rawls, 1958, 1971, 1974). A large number of contributions followed, criticising and extending Foley's approach to distributive justice. The interested reader is referred to Feldman and Kirman (1974), Schmeidler and Vind (1972), Schmeidler and Yaari (unpublished), Varian (1974, 1975), Pazner and Schmeidler (1974, 1978). It soon became apparent that to identify 'fairness' with the 'absence of envy' may not be the correct way of defining fairness. The moral ground behind such an identification was questioned by Rawls (1971). The conflict between Pareto optimility and 'fairness' as defined by Foley was brought into light by Pazner and Schmeidler (1974). In this paper, we shall develop the concept of a 'fair market economy' and examine its characteristics in the context of a fair allocation of goods and resources in the society. Before that, an assessment of some previous work done in this area, is essential.

\section{A review of the analytic framework}

Consider two individuals - Robert and Mary. None of them owns any asset but each of them is endowed with one unit of labour. Robert is more efficient in production than Mary. So his wage-rate $\left(w_{1}\right)$ is greater than that of Mary $\left(w_{2}\right)$. The output, produced and consumed, is denoted by $x$. In Fig. 1, the budget lines for these persons are given by $L M$ and $L N$ respectively. The allocation $(a, b)$ in Fig. 1 describes a free-market equilibrium where both are on their highest attainable indifference curves. The market equilibrium is obviously pareto-optimal but is not fair according to Foley (1967) because Mary envies Robert. In Fig. 1, assuming that the budget line is same for both of them $(L M)$, the allocation $(a, c)$ describes the market equilibrium which is 'fair'. Note, in a competitive economy, the wage rate equals the productivity of labour for both the individuals. Since preferences are assumed to be convex, Mary cannot hire Robert to do her work because that would imply Robert demanding a wage higher than his productivity.

The above example raises two important questions:

(i) When the market equilibrium is not 'fair', is it always possible to achieve an allocation (through a 'lump-sum tax-subsidy' measure) which is fair in the sense that there is no mutual envy present?

(ii) In an economy with productive agents, can the 'absence of envy' be the sole criterion for deciding whether an allocation is 'fair' or not? In Fig. 1, for the sake of fairness, if a lump-sum transfer is made from Robert to Mary, we shall not only be taxing Robert for greater efficiency but also for harder work.

The answer to the first question is disappointing. Under quite reasonable circumstances a 'fair' pareto-optimal allocation may not exist (see Pazner and Schmeidler, 1974). The second question is somewhat uncomfortable and has led economists to new concepts of 'fair allocation' compatible with distributive justice. One such concept is due to Varian $(1974,1975)$ and can be described as follows. In the free market equilibrium, Mary envies Robert. Would she be willing to work hard 


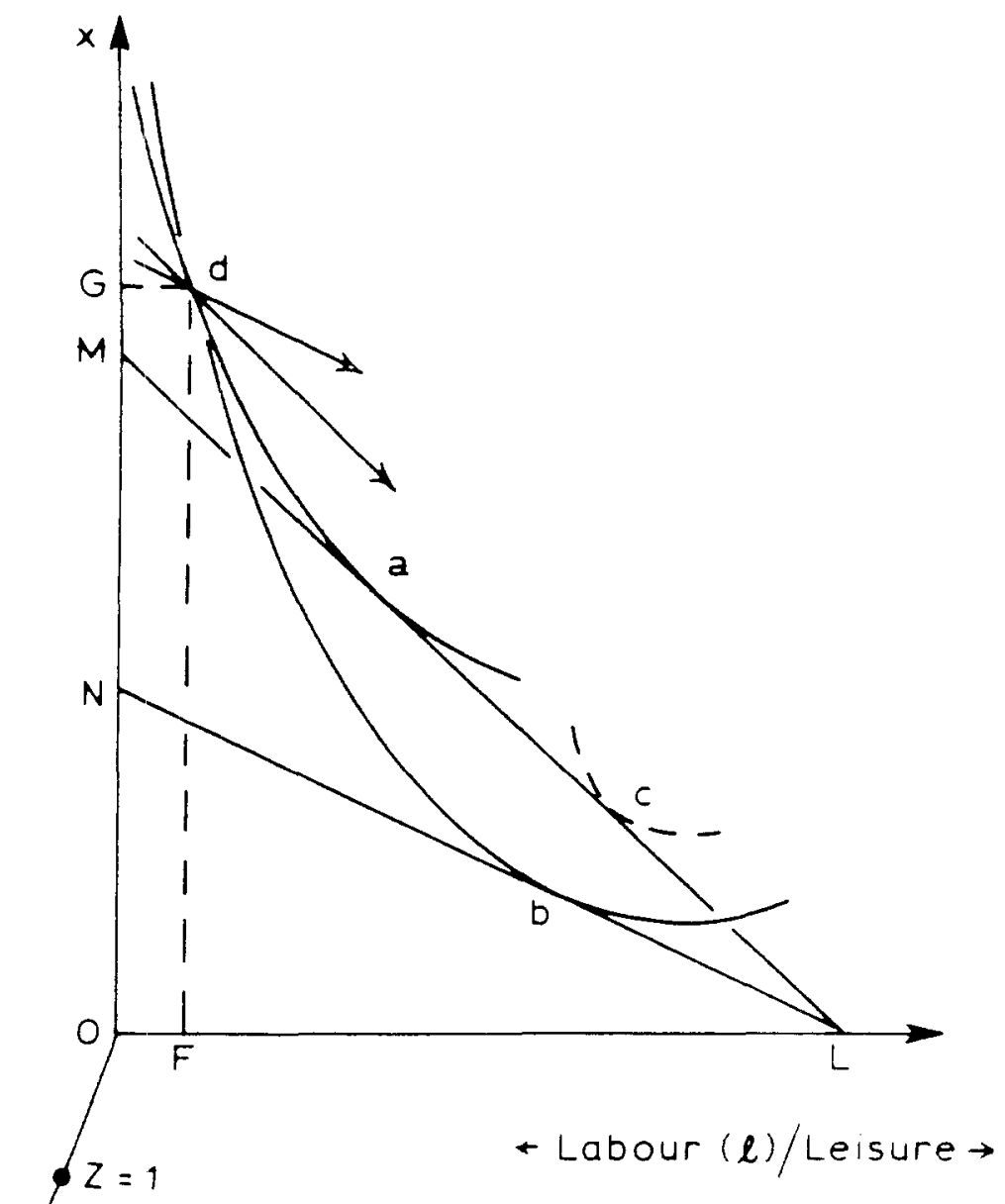

Fig. 1.

enough to produce the amount of goods which Robert is producing? If not, the free market allocation $(a, b)$ is a 'just allocation'. Varian calls it a fair* or $W$-equitable allocation. If Mary or Robert own assets or wealth, Varian would require them to be distributed equally. It is easy to see that any possible free-market allocation in our example is a fair* allocation. If Mary is maximising her utility at ' $b$ ', then any other position on the same budget line $(L N)$ will be rejected by her. The problem with fair ${ }^{*}$-ness as a concept in distributive justice is that it may demand too much from the inefficient person. Suppose, producing the amount of goods which Robert produces would lead Mary to work twenty-two hours a day and she refuses to do that, shall we be justified in concluding that Mary deserves the poverty she is in? By Varian's own (1975) admission the definition is conservative. However, Varian is right in emphasising that a criterion of 'fairness' should also consider the relative efforts which the individuals put in.

Another well-known approach towards distributive justice in allocation owes its origin to Pazner and Schmeidler (1978). Suppose, there exists a hypothetical bundle (the bundle ' $d$ ' in Fig. 1) such that if both Robert and Mary were endowed with it, then each of them would have the levels of satisfaction which they have with allocation $(a, b)$. Pazner and Schmeidler argue that $(a, b)$ may be considered to be a 'just 
allocation' because it is equivalent to the egalitarian distribution $(d, d)$. As in the case of fair*-ness, it is again easy to demonstrate that under reasonable conditions, the market-allocation $(a, b)$ is also an Egalitarian Equivalent Allocation (EEA).

The appeal of an EE-allocation to distributive justice is derived from the fairness of the equality of endowment. Unfortunately, we know that equal endowments do not necessarily satisfy the requirements of distributive justice and less so those for procedural justice. For example, at the point ' $d$ ' in Fig. 1, both the individuals are given ' $O G$ ' goods and ' $F L$ ' work. As Fig. 1 suggests, both Robert and Mary would have been better off by working less and they would do so given a free choice. So at ' $d$ ', two of the fundamental conditions of both distributive and procedural justice-liberty and freedom of choice-are violated. If $(d, d)$ is not admissible as a 'just allocation', the allocation $(a, b)$ looses much of its strength in claiming itself to be distributionally just.

\section{The fair market economy}

We have seen that market allocation ceases to be 'fair' when the levels of efficiency differ among the individuals. Why the levels of efficiency differ? If the answer lies in the difference in past effort (to acquire productive skills), then Fig. 1 is a distorted presentation of the choice problem facing Robert and Mary. We should have added the intensity of past effort to acquire skill as the third dimension ( $Z$-axis) of the choice problem. The unit interval $[0,1]$ could be used to measure the intensity of effort, i.e., $Z=0$ would imply no past effort and $Z=1$ would indicate maximum possible effort. Now, Robert and Mary face the same surface as the constraint of their respective choice problems. If Mary chooses to enjoy her early youth at the cost of a low-paid job in the future and Robert chooses to work hard in his early days in return for a respectable professional career later, they are free to do so. Since the budget-constraint is same for both, it is obvious, that at the time of making the choice there is no mutual envy. If at a later stage in life Mary envies Robert, we can not argue that 'envy' should be the criterion for 'fairness' in this case. As Nozick (1974, p. 50) argued, it is 'relevant to ask whether-someone did something so that he... deserved to have a lower share.'

It is difficult to argue with Nozick on this issue. However, in a large number of cases, the differences in efficiency are not due to past actions but are caused by historic, hereditory or natural environments. People are born ugly (which limits their earning potentials), mentally or physically handicapped, or born to parents who do not care to - or, sometimes cannot - give proper guidance to their children. Is it just that these young people should be condemned to a lower status in the society in comparison with their contemporaries who were not so unfortunate in their birth? This is where the proponents of distributive justice part company whith those who believe that justice simply implies a strict observance of a fair set of rules (see Varian, 1975). The proponents of 'distributive justice' claim the equality of oppor- 
tunity, freedom, wealth and bases of self-respect as the very basis of social justice. If we agree with them, the end-state which emerges from such an initial position of 'equality' should be a fair state. Further, if in another end-state, an agent is worse off in comparison with the end-state emerging from a position of equality, we may regard that end-state to be 'unfair' to this agent. In some sense, the former end-state provides us with minimum requirements of a fair state.

For the purpose of distributive justice, if Mary and Robert had assets we would have required them to be distributed equally. For the sake of simplicity we assume zero-asset position for both the individuals. If we accept equality in the 'beginning of state' as the basis for distributive justice, Robert and Mary (whose efficiencies differ because of natural, hereditory and historical reasons beyond their control) must have the right of equal reward for their labour. In a totalitarian society, the society may claim the ownership of the individuals' labour and offer each person the same wage rate. In a democratic society, the government can impose a proportional income tax and a proportional income subsidy in a way that the effective wage-rate for both the individuals are same.

$$
(1-t) w_{1}=(1+s) w_{2} \quad 0 \leq t \leq 1
$$

Given the same effective wage rate, the revenue realised from Robert's contribution may not be equal to the amount which Mary needs to fulfil her plan. Let $\left(x_{1}^{*}, l_{1}^{*}\right)$ and $\left(x_{2}^{*}, l_{2}^{*}\right)$ describe the equilibrium for Robert and Mary respectively. Please note, we are describing the choice as income-labour choice rather than incomeleisure choice. For notational convenience we are describing the choice as $(x, l)$ rather than $(x, 1-l)$. To bring society's budget to balance, it is required that,

$$
t w_{1} l_{1}=s w_{2} l_{2} \text {. }
$$

Given $w_{1}$ and $w_{2}, l_{1}^{*}$ and $l_{2}^{*}$ are functions of $t$ and $s$. It is possible to show that there exists values of $t$ and $s$ which satisfy (1) and (2). In other words, there exists an uniform effective wage rate which brings the society's budget into balance. The allocation $\left(\left(x_{1}^{*}, l_{1}^{*}\right),\left(x_{2}^{*}, l_{2}^{*}\right)\right)$ corresponding to this equilibrium uniform effective wage rate will henceforth be referred to as the allocation under egalitarian wage policy $(A E W P)$. If the indifference curves are convex to the origin, AEWP is unique.'

Let $R$ stand for 'preferred to or equivalent' and $P$ for 'strictly preferred to'. The subscript $i$ refers to the $i$ th individual.

\footnotetext{
'Both convexity (strict) of the indifference curves and uniqueness of the egalitarian wage rate $w^{*}$ are needed for the uniqueness of AEWP. Theorem 1 proves the existence of $w^{*}$. We are assuming that the demand for $x$ by any agent obeys the law of demand, i.e., $\partial x_{i} / \partial w_{1}>0$. In the context of Theorem 1 , this implies that $\delta D / \delta t<0$. In general equilibrium theory, it is well-known that if we allow' for 'Giffen goods', the competitive equilibrium may not be unique which raises problems with comparative static analysis. A similar problem of comparison also arises here.
} 
Definition 1. If an allocation $A=\left(\left(x_{1}, l_{1}\right),\left(x_{2}, l_{2}\right)\right)$ when compared to AEWP is such that $\left(x_{i}, l_{i}\right) R_{i}\left(x_{i}^{*}, l_{i}^{*}\right)$ for all $i(i=1,2)$ and $\left(x_{i}, l_{i}\right) P_{i}\left(x_{i}^{*}, l_{i}^{*}\right)$ is some $i$, then $A$ is a Weak-Rawls-Fair allocation.

Definition 2. If an allocation $A=\left(\left(x_{1}, l_{1}\right),\left(x_{2}, l_{2}\right)\right)$ is such that, $\left(x_{i}, l_{i}\right) P_{i}\left(x_{i}^{*}, l_{i}^{*}\right)$ for all $i(i=1,2)$, then $A$ is a Rawls-Fair allocation (see Rawls, 1971, p. 62).

Definition 3. An allocation $\left(\left(x_{1}, l_{1}\right),\left(x_{2}, l_{2}\right)\right)$ will be called a 'just allocation' if $\left(x_{i}, l_{i}\right) R_{i}\left(x_{i}^{*}, l_{i}^{*}\right)$ for all $i$. In defining 'just allocation' we have used AEWP as the norm. Any allocation, which is at least as good as the allocation under egalitarian wage policy, is viewed as a fair allocation. ${ }^{2}$ This is in line with the demand for distributive justice (initial position of equality) as discussed earlier. Also note, the above definition can be extended straight away to cover the case of a finite number $(N)$ of agents.

Theorem 1. An equilibrium uniform effective wage rate exists if the market allocation $\left(\left(x_{1}, l_{1}\right),\left(x_{2}, l_{2}\right)\right)$ is a continuous function of the tax-rate, $t$.

Proof. Let $D=s w_{2} l_{2}-t w_{1} l_{1}$ be the deficit of society's budget associated with a certain value of $t$. Using (1),

$$
D=\left\{(1-t) w_{1}-w_{2}\right\} l_{2}-t w_{1} l_{1}=\left(w_{1}-w_{2}\right) l_{2}-t w_{1}\left(l_{1}+l_{2}\right) .
$$

If $t=0$, by Eq. (1), $s>0$ and,

$$
D=\left(w_{1}-w_{2}\right) l_{2}>0 \text {. }
$$

If $t=1-w_{2} / w_{1}$, then $s=0$ and,

$$
D=\left(w_{2}-w_{1}\right) l_{1}<0 \text {. }
$$

Therefore, $\exists t^{*}, 0<t^{*}<1-w_{2} / w_{1}$, such that $D=0$. The equilibrium uniform effective wage rate is given by $\left(1-t^{*}\right) w_{1}=w^{*}$.

Theorem 2. If the indifference maps of both the individuals are identical then the equilibrium uniform effective wage is given by $w^{*}=w_{2}+\left(w_{1}-w_{2}\right) / 2$. In other words, if the preference orderings of both the individuals are identical, then the egalitarian wage rate will lie halfway between the market wage rates.

\footnotetext{
${ }^{2}$ We are assuming, throughout this paper, that the wage rate reflects the efficiency of labour. If wages are determined by a gambling process, it is possible that AEWP is pareto-dominated by some other process of allocation where the wage rates are (at least partially) determined by a gambling process (see Myerson, 1981). In this case, the use of AEWP as the norm of 'just allocation' would be somewhat arbitrary. Further results examining the relationship between fair division and egalitarianism may be found in Thompson (1983).
} 
Proof. If the preference orderings are same for both the individuals, at the egalitarian wage rate $w^{*}, l_{1}=l_{2}$. Using (2) we get $t w_{1}=s w_{2}$. Using this in (1), $\left(w_{1}-w_{2}\right) / 2=s w_{2}$. Since by definition $w^{*}=(1+s) w_{2}$, we get $w^{*}=\left(w_{1}-w_{2}\right) / 2+w_{2}$

Obviously, the allocation of resources by free market does not satisfy the requirements of 'just allocation' when the efficiencies of individuals vary due to 'historic, hereditary and natural reasons'. In the regime of egalitarian wage policy, the worst off will always do better. However, it is pertinent to ask the question, whether by imposing lump-sum taxes and subsidies, a 'just' pareto-optimal allocation can be achieved. It is well known, when the lump-sum transfers are preannounced, the end-state allocation is pareto-optimal. The question is whether there exists a value of lump-sum transfer so that the end-state allocation is 'just'. From Pazner and Schmeidler (1974) we know that there may not exist a lump-sum transfer value for which the end-state is 'fair' in Foley's (1967) sense. We shall show that there exists a value for pre-announced lump-sum transfer for which the end-state allocation is 'just'. Actually, we prove a stronger result. In case of a two-agent economy, there exists a transfer value for which the end-state allocation is RawlsFair, i.e., both the persons are better off in comparison with a regime of egalitarian wage-policy. For an $\mathrm{N}$-agent economy, this existence result can be extended only to a Weak Rawls-Fair allocation.

Let us define $T_{1}^{*}=t_{1}^{*} w_{1} t_{1}$ where $t_{1}^{*}$ is the tax-rate imposed on individual 1 (Robert) in a regime of egalitarian wage policy. We shall show that if a transfer of $T_{1}^{*}$ from Robert to Mary is pre-announced, then in the end-stage, both of them will be better off in comparison with an egalitarian wage regime. Note, in a two-agent economy $T_{1}^{*:}=-T_{2}^{*}$. Therefore, in a two-agent economy, we shall talk about transferring $T^{*}$ from Robert to Mary without any ambiguity. The following definition of fiar transfers apply to an $N$-person economy.

Definition 4. Let $T_{i}^{*}=t_{i}^{*} w_{i} l_{i}$ where $t_{i}^{*}$ is the tax rate imposed upon the $i$ th individual (subsidies are negative taxes) in a regime of egalitarian wage policy. A market economy with pre-announced transfers $\left\{T_{1}^{*}, \ldots, T_{n}^{*}\right\}$ is called a Fair Market Economy.

Theorem 3. The allocation in a two-agent Fair Market Economy is a Rawls-Fair allocation.

Proof. Let $U_{i}=U_{i}\left(x_{i}, 1-l_{i}\right), \partial U_{i} / \partial x_{i}>0, \partial U_{i} / \partial l_{i}<0$, describe the utility function underlying the preferences of the $i$ th individual. Consider an egalitarian wage regime with $w^{*}$ as the effective wage rate for both the individuals (AEWP). Since both are maximising utility,

$$
\mathrm{d} U_{i}=\left(\left(\partial U_{i} / \partial x_{i}\right) w^{*}+\partial U_{i} / \partial l_{i}\right) \mathrm{d} l_{i}=0 \quad i=1,2 .
$$

With the pre-announced transfer $T_{1}^{*}$ in a Fair Market Economy, the allocation 


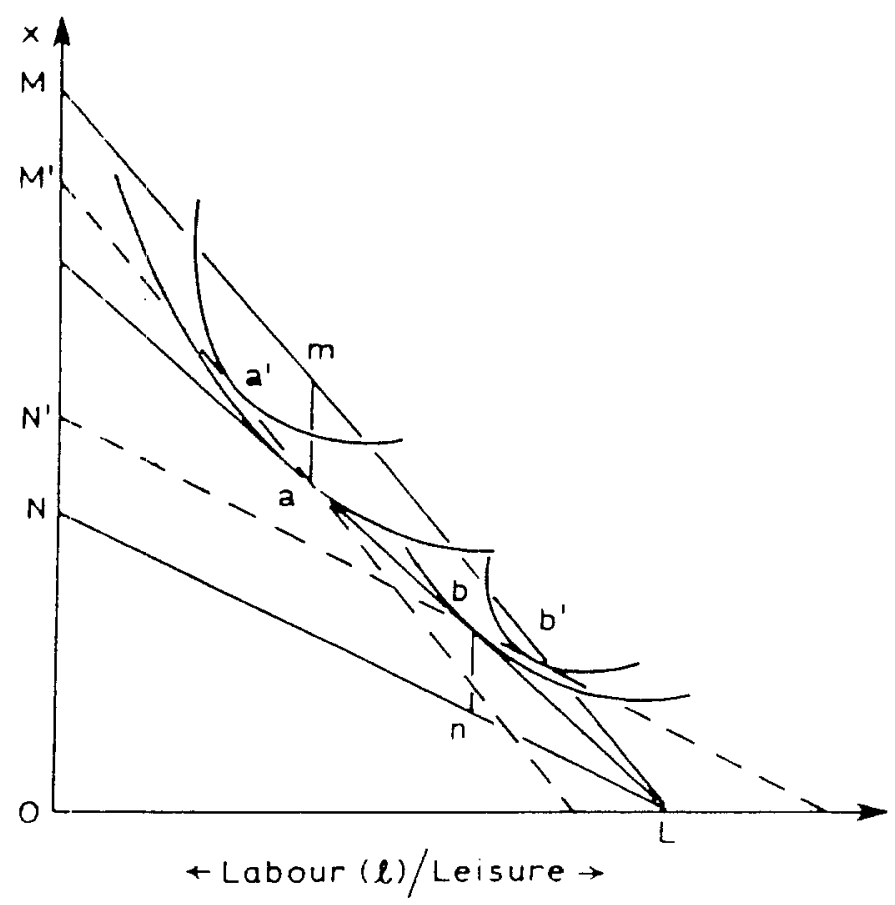

Fig. 2.

$\left(x_{i}^{*}, l_{i}^{*}\right)$ is still available to the $i$ th individual but the wage rate (the rate of transformation between goods and leisure $\left.\left(1-l_{i}\right)\right)$ is $w_{i}$. For individual 1 (Robert), $w_{1}>w^{*}$, hence

$$
d U_{1}=\left(\left(\partial U_{1} / \partial x_{1}\right) w_{1}+\partial U_{1} / \partial l_{1}\right) \mathrm{d} l_{1}>0
$$

Therefore individual 1 can increase his utility by working harder. For, individual 2 (Mary), $w_{2}<w^{*}$. Therefore, $\mathrm{d} U_{2} / \mathrm{d} l_{2}<0$, and Mary will increase her utility by having more leisure. Thus, in a Fair Market Economy both the agents are better off.

Theorem 3 has been illustrated diagrammatically in Fig. 2. Under egalitarian wage policy, the equilibria of Robert and Mary are denoted by $a$ and $b$ respectively. The transfer $T^{*}$ (tax to Robert) is represented by ' $a m^{\prime}$ ' which is same as Mary's subsidy, ' $b n$ '. If instead of an egalitarian wage policy we have a Fair Market Economy with transfer $T^{*}$, then Robert and Mary will choose $a^{\prime}$ and $b^{\prime}$ respectively. Clearly, Robert prefers $a^{\prime}$ to $a$ and Mary prefers $b^{\prime}$ to $b$. Therefore $\left(a^{\prime}, b^{\prime}\right)$ is a Rawls-Fair allocation. In Fig. 1, equality of lump-sum tax on Robert's income (am) with lumpsum subsidy to Mary's income is required for balancing the budget of the economy. However, its impact on the income-leisure choice of Robert and Mary is not going to be symmetric, because subject to the lump-sum transfer, both are allowed to receive their free-market wages which differ due to differences in productivity.

There is an implicit result in Theorem 3 which requires our attention. In a Fair Market Economy, in comparison with an economy with egalitarian wage policy, the relatively efficient person works harder and the relatively inefficient person works less. Quite often, this is misinterpreted as an indication of the laziness of the ineffi- 
cient or the poorly-paid person. Nothing special in Mary's preferences indicates that Mary prefers leisure to work in comparison with Robert. The reason, why Robert will work harder and Mary will work less, lies in the substitution effect. Utility-level can be increased by working harder and consuming the fruits of harder work or by working less and having more leisure. In case of 'efficient Robert' the comparative advantage lies in working harder and consuming more, whereas in case of 'handicapped Mary' the relative advantage lies in enjoying more leisure. For the sake of simplicity, we confined our discussion to a two-person economy. It is easy to see that our discussion can readily be extended to cover the case of a finite number of agents. For example, in Theorem 1, we may define $D=\sum_{t=1}^{N} t_{i}, l_{\text {, where }} t_{i}<0$ in case of subsidy to individual $i$. To balance the budget of the society we require $D=0$. Without any loss of generality, assume that individual 1 is most efficient and the Vth individual is least efficient. If we set the egalitarian effective wage rate $w^{*}=w_{1}$, then $D>0$. On the other hand, if $w^{*}=W_{N}$, then $D<0$. Under the assumption of continuity of $\left(w_{1}, l_{i}\right)$ with respect to changes in the effective wage rate, there must exist a $w^{*}$ lying between $w_{1}$ and $w_{1}$ for which $D=0$. If $x_{1}=w_{i} l_{1}$ is a normal good for each $i$, then $w^{*}$ is also unique. Note, in case of more than two agents with different levels of efficiency, in general the allocation in a fair market economy is Weakly-Rawls-Fair. If $w_{j}^{\prime}=w^{*}$, then the $j$ th person will neither be taxed nor subsidized. Therefore, he is as well off in a fair market economy as he is under AEWP. Anyway, allocation in a fair market economy is a paretoimprovement upon AEWP so long as efficiency among some individuals differs.

\section{Effort and fairness}

So far we assumed that the differences in efficiency among individuals are solely due 10 hereditory or natural advantages, and engaged ourselves in a discussion on how to neutralize this relative advantage or privilege. In reality, efficiency is not always related only to 'privileges'. Past efforts to acquire productive skills $(Z)$ also play an important role. This creates a problem for the straight forward construction of the fair market economy described in the last section. It is possible that 'efficient' Robert may have a preference ordering which makes him more interested in enjoying his early youth. On the other hand, given the same constraint, Mary's preference ordering may induce her to such a degree of effort to acquire skills, that in the working life Mary is more efficient than Robert. In a fair market economy, as described in the previous section, a lump-sum transfer will be made from Mary to Robert. Obviously, it is unjust to tax 'sincere and handicapped' Mary for subsidizing 'funloving but efficient' Robert. This is clearly the point raised by Nozick (1974, p. 50). In this section, we shall suggest a solution to this problem. In doing so, we shall assume that before deciding upon the effort-level to acquire skills $\left(Z_{i}\right)$, each individual has perfect information regarding the tax (subsidy) rate to be applied to him. Essentially, it is a pure-strategy game with perfect information played between 
each individual and the government. The question is, does there exist a social strategy in income transfers so that a fair market economy prevails? It shall be noted that if the government adopted a mixed strategy in announcing transfers or there is any uncertainty in the system, there would be a timing problem as to whether we should consider the ex-ante or ex-post utility function (see Myerson, 1981).

Since skills can be acquired by putting in effort $\left(Z_{i}\right)$, the wage rates $\left(w_{i}\right)$ must depend on $Z_{i}$. We assume,

$$
w_{i}=w_{i}\left(Z_{i}\right), \quad w_{i}^{\prime}>0, \quad w_{i}^{\prime \prime}<0, \quad i=1,2 .
$$

The budget constraints for the individuals are given by,

$$
x_{i}=w_{i}\left(Z_{l}\right) l_{i}, \quad 0 \leq Z_{i}, \quad l \leq 1, \quad i=1,2,
$$

subject to which they are maximising their utility,

$$
u_{i}=u_{i}\left(x_{i}, 1-l, Z_{i}\right), \quad i=1,2 .
$$

If the functions $w_{i}\left(Z_{i}\right)$ were identical for all the individuals, then the market allocation would have been fair. We did not have to bother about distributive justice. Since the degree of hereditory privileges differs from individual to individual, the function $w_{i}\left(Z_{i}\right)$ is not identical for all $i$. Any tax (or subsidy) imposed on $w_{i}$ affects the budget constraint which becomes

$$
x_{i}=\left(1-t_{i}\right) w_{i}\left(Z_{i}\right) l_{i}
$$

and consequently the choice of $\left(w_{i}, 1-l_{i}, Z_{i}\right)$ is affected.

Since skills can be acquired by effort, transfers of income from a more efficient person to a less efficient individual can not be justified on the ground of 'fairness'. For example, suppose $w_{1}=\operatorname{Minimum}\left(w_{1}, w_{2}\right)$, where individual 1 has hereditory privileges but he did not care to put in enough effort to acquire skills. Individual 2 , although handicapped, has acquired high level of skill with a lot of effort. It is certainly not fair to transfer income from individual 2 to individual 1 . In a market economy, we have to measure the gap in wages at a constant level of effort to measure the impact of hereditory privileges on productivity.

Without any loss of generality, suppose $Z_{1}<Z_{2}$. Let the society pick up the least effort level $Z_{1}$ as the basis for comparing the distortion of the wage rate caused by hereditory advantages. In the context of our previous discussions, we assume that the society measures the advantage of Robert at the effort-level $Z=\operatorname{Min}\left(Z_{1}, Z_{2}\right)$. Throughout our discussion we shall maintain this assumption. The reason is, if the standard effort level $Z>\operatorname{Min}\left(Z_{1}, Z_{2}\right)$ an effort adjusted fair market economy may not exist. To illustrate this point, let $Z=\operatorname{Max}\left(Z_{1}, Z_{2}\right)=Z_{2}$ and $w_{1}\left(Z_{2}\right)-w_{2}\left(Z_{2}\right)>$ $K w_{1}\left(Z_{1}\right)>0$ where $K$ has a large positive value. In words, Robert could be much more efficient than Mary if he did put in as much effort as Mary did. However, he has put in so little effort, that his wage rate is extremely low in comparison with that of Mary. For Robert, $w_{1}\left(Z_{2}\right)$ is an imputed wage rate vis-a-vis his actual wage rate $w_{1}(Z)$. If the imputed wage-rate is much higher than the actual wage rate, the 
tax-bill of Robert may be more than his wage. Hence, 'fair' transfers may not be feasible. It is possible that a feasible fair set of transfers may exist with a choice of $Z=\phi\left(Z_{1}, Z_{2}\right)>\operatorname{Min}\left(Z_{1}, Z_{2}\right)$ but there is no guarantee that it will exist.

Consider the interval $I=[0,1]$ and $I^{2}=I \times I$. Define,

$$
\begin{array}{ll}
C .1 & Z=\left(Z_{1}, Z_{2}\right) \in I^{2}, \\
C .2 & Z^{\prime}=\operatorname{Min}\left(Z_{1}, Z_{2}\right), \\
C .3 & w\left(Z^{\prime}\right)=\left(w_{1}\left(Z^{\prime}\right), w_{2}\left(Z^{\prime}\right)\right) .
\end{array}
$$

Starting from an arbitary effort vector $Z, Z^{\prime}$ is the reference (standard) effort level chosen by the society with reference to which the imputed wage vector $w(Z$ ') has been calculated in a perfect information economy. Next, we define a mapping from reference wages to the fair tax (subsidy) structure.

C.4

$$
t\left(w\left(Z^{\prime}\right)\right): w\left(Z^{\prime}\right) \rightarrow t=\left(t_{1}, t_{2}\right)
$$

where the fair transfer (tax-subsidy) rates $t_{1}, t_{2}$ are explained below. If individuals were maximising their utility given the wage-rates $w_{i}\left(Z^{\prime}\right)$ but with the given actual effort level $Z_{i}$, we could write their choice problem as,

Maximise $u_{i}=u_{i}\left(x_{i}, 1-l_{i}, Z_{i}\right)$,

Subject to: $x_{i}=\left(1-t_{i}\right) w_{i}\left(Z^{\prime}\right) l_{i}$.

By Theorem 1, we know that there will exist a fair transfer-structure, provided the solution $x_{i}, l_{i}$ is continuous in $t_{i}{ }^{3}$ The fair transfer rates will be given by $\left(1-t_{i}\right) w_{i}\left(Z^{\prime}\right)=w^{*}$, where $w^{*}$ is the uniform effective wage rate in Theorem 1 . These are the chosen $t_{i}$ 's in C.4. Next, we define the mapping $Z(t)$.

C.5 $Z(t): t \rightarrow Z=\left(Z_{1}, Z_{2}\right)$, where $Z_{1}, Z_{2}$ are derived from the solution of the problem:

Maximise $u_{i}=u_{i}\left(x_{i}, 1-l_{i}, Z_{i}\right)$,

Subject to: $x_{i}=\left(1-t_{i}\right) w_{i}\left(Z_{i}\right) l_{i}$.

In the above problem $Z_{i}$ is a choice variable given the parameter $l_{i}$. The constructions C.1-C.5 define a mapping $f: I^{2} \rightarrow I^{2}$ as follows:

$$
f: Z \rightarrow Z^{\prime} \rightarrow w\left(Z^{\prime}\right) \rightarrow t\left(w\left(Z^{\prime}\right)\right) \rightarrow Z(t), \quad Z \in I^{2} .
$$

Obviously, if there exists a $Z \in I^{2}$ which is invariant under the mapping $f$, then $c\left(w\left(Z^{\prime}\right)\right)$ is a feasible, fair transfer-rate (tax-subsidy rate) with the reference level of $X=\operatorname{Min}\left(Z_{1}, Z_{2}\right)$.

\footnotetext{
'Since $Z^{\prime}=\operatorname{Min}\left(Z_{1}, Z_{2}\right)$, the impuled wage rates are less than the actual wage rates, i.e., $\left.w_{i}\left(Z^{\prime}\right)<w_{(}, Z_{1}\right)$. Therefore, lump-sum transfers, $l_{i} w_{,}\left(z^{\prime}\right) l_{1}$, are feasible, being less than the actual earn$\operatorname{lng} w_{i}\left(Z, l_{1}\right.$
} 
Theorem 4. In the context of selecting a reference level of $Z=\operatorname{Min}\left(Z_{1}, Z_{2}\right)$, the mapping f has a fixed point if (i) $w_{i}\left(Z_{i}\right)$ is continuous in $Z_{1}$. (ii) the uniform effective wage-rate $\left(w^{*}\right)$ in $C .4$ is continuous in $w_{i}^{\prime}\left(Z^{\prime}\right)$ and (iii) the choice of $Z_{i}$ in $C .5$ is continuous in $t_{i}$.

Proof. $Z^{\prime}=\operatorname{Min}\left(Z_{1}, Z_{2}\right)$ is continuous in $Z \in I^{2}$. By conditions (i) and (ii) the egalitarian wage rate $\left(w^{*}\right)$ is continuous in $Z^{\prime}$. Therefore, $t_{i}=1-1 w^{*} / w_{i}\left(Z^{\prime}\right)$ is continuous in $Z$. By condition (iii) $Z(t)$ in $C .5$ is continuous in $Z$. This establishes the continuity of the mapping $f$. Since $f$ is defined on $I^{2}$ which is convex and compact in $R^{2}$, by Brouwer's fixed point theorem, the mapping leaves at least one fixed point $Z^{*} \in I^{2}$. $\square$

It is easy to see that the theorem can easily be extended to cover the case of a finite number of agents. For the purpose of the next definition, assume $Z^{*}$ to be unique.

Definition 5. Let $T_{i}^{*}\left(Z^{*}\right)=t_{i}^{*} w_{i}\left(Z^{*}\right) l_{i}^{*}$, where $t_{i}^{*}$ is the tax rate imposed upon the ith individual (subsidies are negative taxes) in a regime of egalitarian wage policy with $Z=Z^{*}$ chosen as the reference level of $Z$. A market economy with preannounced transfers $\left(T_{1}^{*}\left(Z^{*}\right), \ldots, T_{n}^{*}\left(Z^{*}\right)\right)$ is called an Effort Adjusted Fair Market Economy (EAFME).

It is important to note that in an EAFME the privileged person has to pay taxes and the relatively handicapped person always receives subsidies. However consideration is shown to the tax-payer by choosing the reference effort-level $(Z)$ as the minimum of the effort undertaken by the agents in the economy.

What happens if $Z^{*}$ is not unique? The choice of $Z^{*}$ also determines the minimum effort put up by an individual in the economy. If, for example, $Z^{*}$ has two values $Z_{*}^{*}$ and $Z_{b}^{*},\left(Z_{a}^{*}>Z_{b}^{*}\right)$, a technocratic society would perhaps choose $Z^{*}=Z_{a}^{*}$ to raise the minimum level of efficiency. In a more relaxed, less competitive society perhaps the choice of $Z^{*}=Z_{b}^{*}$ would be more appealing. This an issue which is related to social values and attitudes rather than the principle of distributive justice.

\section{Conclusion}

We shall conclude by summarizing the contribution of this paper. In an economy where the productive efficiency of the individuals differ, Foley's concept of 'Tairness' is known to be neither 'fair' nor compatible with pareto optimality. In this paper we have characterized a fair market economy which is at least Weakly RawlsFair. In response to the criticisms laid by Nozick and others, we have extended the concept of a fair market economy taking into account the past efforts to acquire productive skills and the sacrifice involved. The allocation in an effort adjusted fair market economy is not the only allocation which meets the demand for distributive 
justice. However, based on the principle of a rational rectification of hereditory privileges and handicaps, it certainly has an attraction to those who believe in the principle of distributive justice.

\section{Acknowledgment}

The author is grateful to the referee of this journal for constructive suggestions. He also wishes to thank H. Varian, T. Bergstrom, L. Blume and other participants at the Michigan/U.W.O. conference on economic theory.

\section{References}

K.J. Arrow and F.H. Hahn, General Competitive Analysis (Olver and Boyd, Edinburgh, 1971).

K.J. Arrow, Some ordinalist-utilitarian notes on Rawls' Theory of Justice, J. Philosophy 70 (1973) 245-263.

R.W. Boadway and N. Bruce, Welfare Economics (Basil Blackwell, Oxford, 1984)

R.W. Boadway, Integrating equity with efficiency in applied welfare economics, Ouarterly $\mathbf{J}$. Econom. 90 (1976) $541-556$.

1.M. Buchanan and W.C. Bush, Poltical constraints with contractual redistribution. American Econom. Rev. 64 (1974) 153-157

1. E. Dubins and E.H. Spanier, How to cut a cake fairly, American Math. Monthly 68 (1971), 1-1)

A. Feldman and A. Kirman, Fairness and Envy, American Econom. Rev. 64 (1974) 495-1005.

1). Foley, Resource allocation and the public sector, Tale Econom. Essays 7 (1967) $45-48$.

D.C. Mueller, Achieving just policy, American Econom. Rev. 64 (1974) 1+7-152

I. (i. Murphy, Justifying departure from equal treatment, The J. Philos. 81 (1984) 587 -593.

R.B. Myerson, Utilitarianism, egaliarianism and the timing effect in social chote problems, Econometrica 49 (1981) 883-897.

R. Norick, Anarchy, State and Utopia (Basic Books, New York, 1974).

E.A. Pazner and D. Schmeidler, A difficulty in the concept of fairness, Rev. Econom. Studies 41 (1974) $441-443$.

E.A. Pazner and D. Schmeidler, Egalitarian equivalent allocations: a new concept of economic equity. Quarterly J. Econom. 92 (1978) 671-687.

1. Rawls, A Theory of Justice (Harvard University Press, Cambridge, Mass.. IY-1).

1. Rawls, Justice as Fairness. Philos. Rev. 67 (1958) 164-194.

1. Rauls, Some reasons for the maximin criterion, American Econom. Rev. 64 (1974) 141-146

N. Rescher, Distributive Justice (Bobbs-Merrill Company, New York, 1966)

1). Schmeidler and K. Vind, Fair net trades, Econometrica 40 (1972) 637-642.

D. Sithmeidler and M. Yaari, Fair allocations, unpublished

A. Sen. Collective Choice and Social Welfare (Holden-Day, San Francisco 1970 )

W. Thompson, Problems of fair division and the egalitarian solution, I. Econom. Theory 31 (1983) $211-225$

H.R. Varian, Equity, envy and efficiency, J. Econom. Theory y (1974) 63-01

H.R. Varian, Distributive justice, weltare economics and the theory of hamesh, Philos. Public Aftairs $4(1975) 223-247$.

k. Vind, Edgeworth allocation in an exchange economy with many traders, Internat. Econom. Rev. $(1964) 165-177$.

B.A. Wickstroem, Economic justice and economic power: an inquiry into distributive justice and poltical stability. Public Choice 43 (1984) 225-249

First published in Mathematical Social Sciences (1987) 14(3), 225-237. 